\title{
Site characteristics of the high Antarctic plateau
}

\author{
Michael C. B. Ashley \\ School of Physics, University of New South Wales, Sydney NSW 2052, Australia \\ email: m.ashley@unsw.edu.au
}

\begin{abstract}
A brief review is given of the major results from the last twenty years of astronomical site-testing in Antarctica. Suggestions are made for how to resolve some outstanding questions, such as the infrared sky background at Antarctic sites other than South Pole station.
\end{abstract}

Keywords. site testing, atmospheric effects, techniques: photometric

\section{Introduction}

The last twenty years has seen observational confirmation that the unique atmospheric conditions over Antarctica hold many benefits for astronomy. This brief review does not attempt to be all-encompassing. I have concentrated on a few site characteristics, and with a bias towards those relevant for optical, infrared, and terahertz astronomy. For each site characteristic I also briefly comment on what measurements remain to be made.

In the early 1990s it was realised that there were clear theoretical reasons for Antarctica to be an excellent observatory site. For example, the cold atmosphere, low precipitable water vapor, low aerosol concentration, and relatively high altitude of the Antarctic plateau, should lead to very low infrared and sub-mm backgrounds, and high sky transparency.

There were also some not-so-obvious advantages, such as a predicted "cosmological window" at 2.27-2.45 $\mu \mathrm{m}$ resulting from a natural gap in airglow emission (Lubin 1988, Harper 1989), and the possibility of "superseeing" following from the unique Antarctic atmospheric conditions (Gillingham 1993).

And there were some major uncertainties, most notably the fraction of cloudy skies over Antarctica in winter.

Quantifying the site conditions has occupied many groups and produced many dozens of scientific papers over the past twenty years (see Burton 2010 for a review).

\section{Astronomical seeing and atmospheric turbulence}

The movement of the air above the Antarctic plateau is dominated by very low velocity katabatic winds at ice level, and the polar vortex higher up; the high altitude jet streams that are common in mid-latitudes are absent. These unique conditions lead to a highly turbulent, but thin, boundary layer near the ice, with the prospect of potentially excellent "free-atmosphere" conditions above it.

A direct measurement of the seeing is difficult since it requires a relatively large telescope above the boundary layer, hence we rely on measurements from microthermal sensors on balloons and towers, and instruments such as the DIMM, SCIDAR, SODAR, and MASS. The key parameters we need to determine are the boundary layer thickness, the free atmosphere seeing, the isoplanatic angle and the coherence time. 


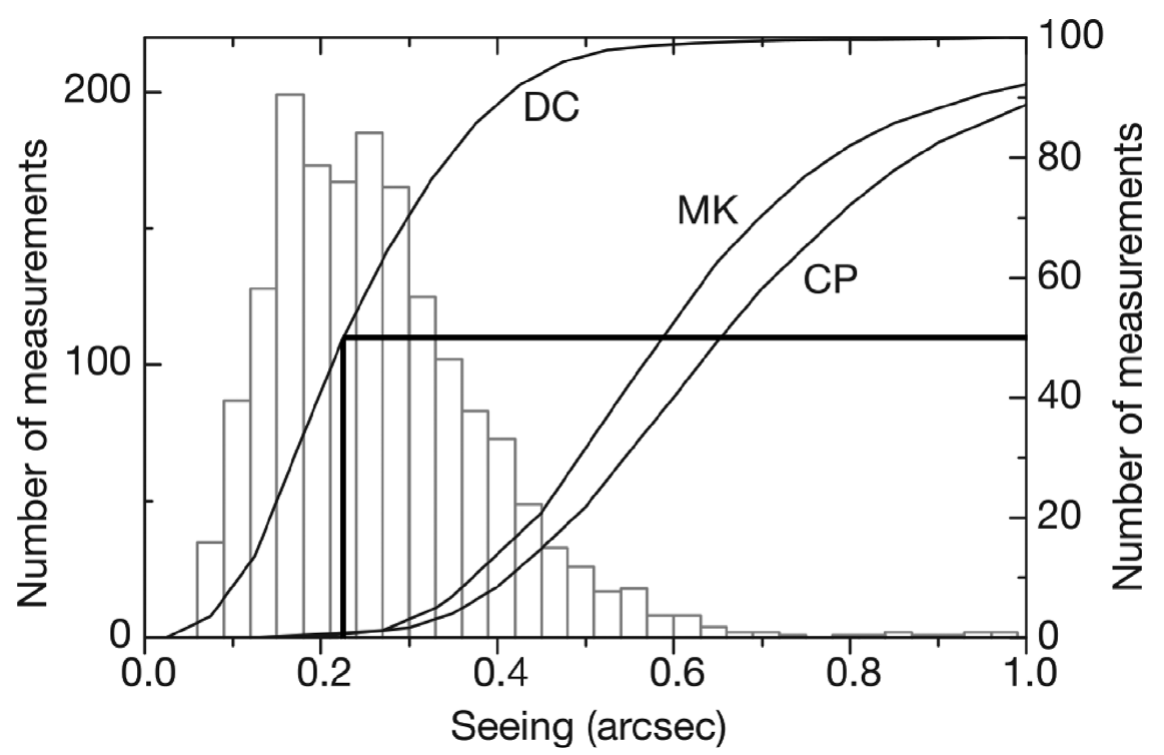

Figure 1. Histogram and cumulative distributions of Dome $\mathrm{C}$ seeing above $30 \mathrm{~m}$ from MASS combined with SODAR, and cumulative distributions of seeing at Dome C (DC), Mauna Kea (MK), and Cerro Paranal (CP). The median Dome C seeing is $0.23^{\prime \prime}$. From Lawrence et al. (2004).

The turbulent boundary layer height at the South Pole was first measured by Neff (1981) with a SODAR (sonic radar). Marks et al. $(1996,1999)$ used microthermal sensors at the South Pole to show that the boundary layer height was typically $\sim 220 \mathrm{~m}$ and that above this the median free atmosphere seeing was $0.32^{\prime \prime}$. On the ice at South Pole, the seeing was a disappointing 1.6" (Loewenstein et al. 1998).

The poor seeing at ice level saw many astronomers lose interest in Antarctica for optical astronomy. However, interest was again ignited when Lawrence et al. (2004) used a MASS and a SODAR at Dome C during wintertime, to demonstrate $0.23^{\prime \prime}$ median seeing (Figure 1) above a boundary layer that was less than $30 \mathrm{~m}$ in height - a height that is less than that of many mid-latitude telescopes. Note that there is an error in the abstract of Lawrence et al. (2004): they state the median seeing was $0.27^{\prime \prime}$; this should be mean seeing; the median is $0.23^{\prime \prime}$ as is clear from the text of their paper and Figure 1.

Given the stunning result from Lawrence et al. (2004), replication of their results was vital, and this has now been done through several independent means. There have been hundred of thousands of DIMM measurements from Dome C, and extensive balloonborne microthermal campaigns (see, e.g., Agabi et al. 2005, Aristidi et al. 2005, 2009 and Trinquet et al. 2008); these papers show $\sim 0.36^{\prime \prime}$ median seeing above a $25-40 \mathrm{~m}$ boundary layer. It is worth noting that DIMM measurements are always upper limits on the seeing, since DIMMs are affected by local turbulence. At Dome C, when the DIMM is on the top edge of the Concordia building, there are good reasons to expect turbulence created by the building itself, both from the tens of kilowatts of heat from the building, and the effect of the building on the airflow.

Giordano (2012) analysed single-star SCIDAR data from Dome C in 2006 to show that the median seeing was less than $0.3^{\prime \prime}$, the isoplanatic angle was greater than $6.9^{\prime \prime}$, and the coherence time was greater than $10 \mathrm{msec}$. 


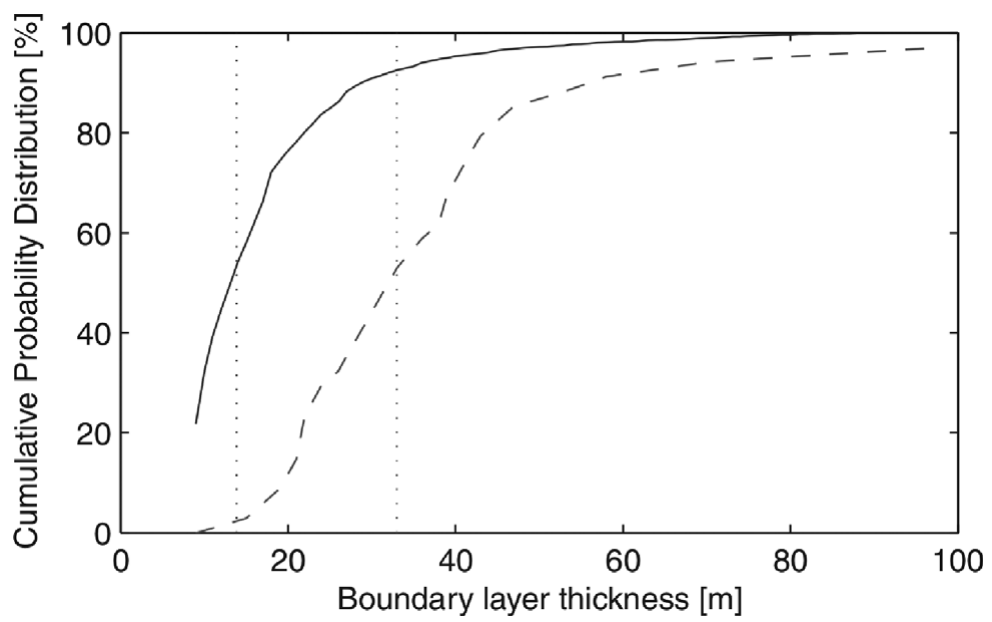

Figure 2. Cumulative probability distributions of the boundary-layer thickness over Dome A using a sonic radar during 2009 (solid line), and Dome C during 2005 (dashed line). Data for Dome $\mathrm{C}$ are from Trinquet et al. (2008). The median boundary-layer thicknesses for Dome A and Dome $\mathrm{C}$ are $13.9 \mathrm{~m}$ and $33 \mathrm{~m}$, respectively. Above this height, a telescope would be in the free-atmosphere for half the time. From Bonner et al. (2010).

The most definitive measurements of the height of the boundary layer on the Antarctic plateau have been made by the Snodar instrument at Dome A (Bonner et al. 2010, see Figure 2). Snodar is a sonic radar that was purpose built to probe turbulence close to the ice with $1 \mathrm{~m}$ resolution (Bonner et al. 2009). The results showed a sharp (< $1 \mathrm{~m})$ transition between turbulence and non-turbulence. Winterover scientists at Dome $\mathrm{C}$ have also anecdotally reported that the transition zone is as thin as centimetres. These observations gives confidence that the height of the boundary layer can be unambiguously defined to better than a metre, and that a sonic radar is the best instrument to measure it. DIMMs and balloons are not able to measure the boundary layer height to this accuracy: DIMMs rely on a statistical analysis of thousands of observations above and below the boundary layer; balloons are affected by wake and limited spatial resolution. A sonic radar can make the measurement in one second, and produce detailed high time resolution plots of the behaviour of the layer.

Theoretical predictions of the boundary layer heights and free-atmosphere seeing over the entire continent were made by Swain and Gallée (2006). Lascaux et al. (2011) have used a mesoscale $(1 \mathrm{~km}$ resolution) model of atmospheric circulation to predict seeing, and they showed a good agreement with observations. Interestingly, they predict that the seeing at Dome A will be better than that at Dome C by a factor of about 0.75 .

In summary then, we have good agreement between theory and independent measurements taken with microthermals, DIMM, SCIDAR, Snodar, and MASS.

One important consequence of the atmospheric turbulence distribution is that the ultimate photometric limit from scintillation is significantly improved over mid-latitude sites. For example, for $60 \mathrm{~s}$ observations on a $4 \mathrm{~m}$ telescope Kenyon et al. (2006) predicted a scintillation limit of $52 \mu \mathrm{mag}$ at Dome C, and $\sim 200 \mu \mathrm{mag}$ for Chile and Mauna Kea.

For the future, we need to measure the seeing at the other high plateau sites: Domes A and F. These measurements are best made with a MASS. The outer-scale of turbulence could be usefully measured. It would also be worthwhile to send a high-resolution sonic radar (e.g., Argentini et al. 2012) to Dome C. Seeing measurements with a DIMM are not ideal since they are upper limits and are affected by local turbulence from the site. 


\section{Precipitable water vapour}

The total column of precipitable water vapour (PWV), and its stability, is of crucial importance since it strongly affects the atmospheric transmission and background radiation. PWV is particularly important in the terahertz, since new windows can be opened up. Even in the optical, PWV has a significant effect in the red, as shown in Figure 3.

Simply speaking, the reason that the air above Antarctica has extremely low PWV is that the air is so cold that most of the water has frozen out. At $100 \%$ relative humidity, the Antarctic air in wintertime has about the same water content (a few parts per million) as a cylinder of commercial dry nitrogen.

There have been many measurements of PWV from Antarctica over many years, primarily from the South Pole. Recently, Yang et al. (2010) measured PWV above Dome A at $661 \mathrm{GHz}(453 \mu \mathrm{m})$ and showed excellent agreement with satellite data (Figure 4). Tremblin et al. (2011) reported on three years of sub-mm sky opacity measurements from Dome C, and obtained reasonable agreement with the IASI interferometer on the METOP-A satellite. Sims et al. (2012) went on to show good agreement for Dome A between three different satellite instruments (Figure 5). A good case can now be made that further measurements of PWV from the ground can be replaced with satellite data, which have the added advantage of covering the whole continent. Ground-based measurements are still useful if you need higher temporal resolution that the satellites can give.

In many ways, the absolute PWV level is not as important as its stability. In both respects, Antarctica has far superior conditions to the best mid-latitude sites (e.g., Cerro Chajnantor).

One area in which Cerro Chajnantor wins is in "dry air opacity", i.e., the atmospheric opacity when no water vapour is present. Dry air opacity comes from collisionally induced multipole moments in nitrogen and oxygen molecules. The increased altitude of Cerro Chajnantor $(5600 \mathrm{~m})$ compared with Dome A $(4100 \mathrm{~m})$ results in less nitrogen and oxygen above the site, and so the dry air opacity is less. However, dry air opacity is of little practical consequence since it is highly stable: its only effect will be to slightly increase integration times. Variations in opacity over short timescales are far more important, and these are dominated by fluctuations in PWV.

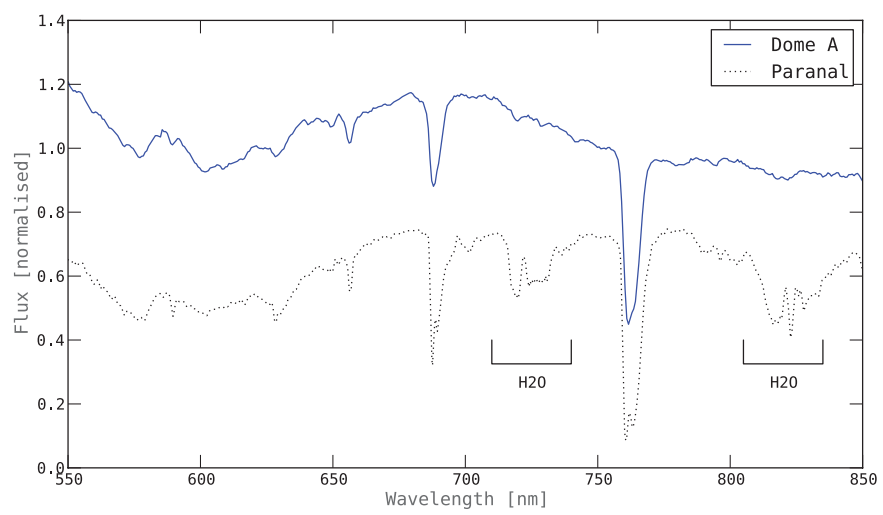

Figure 3. Comparison of Dome A and Paranal twilight sky spectra. The lack of $\mathrm{H}_{2} \mathrm{O}$ absorption in the Dome A spectrum is evident. Both spectra were obtained while the Sun was $\sim 1.4^{\circ}$ below the horizon. The Dome A spectrum has been offset by +0.3 . From Sims et al. (2012). 


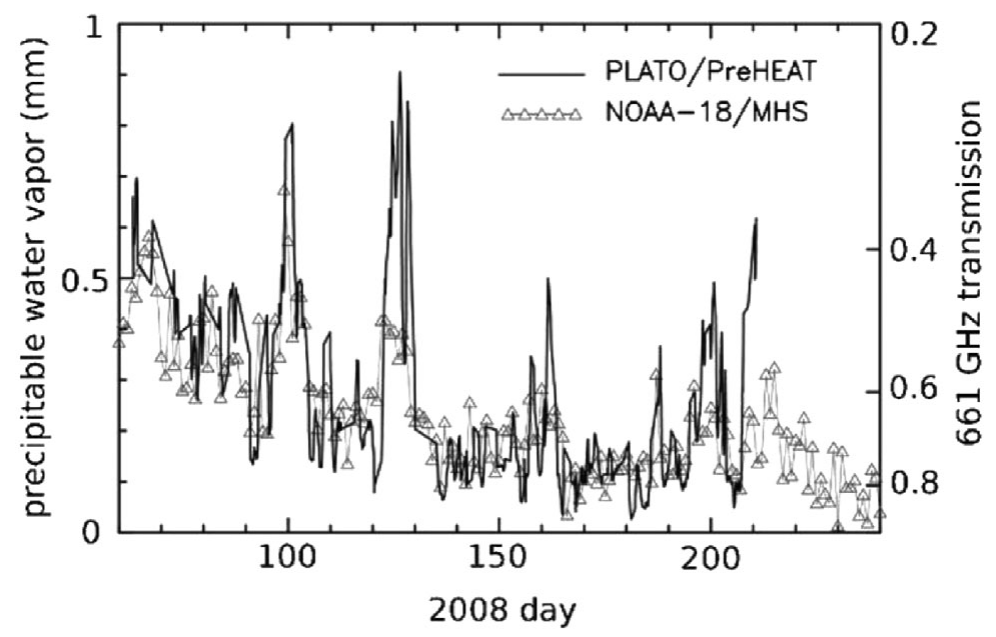

Figure 4. A comparison between satellite measurements of precipitable water vapour above Dome A (the MHS instrument on board NOAA-18) with ground-based of $661 \mathrm{GHz}$ transmission from the Pre-HEAT/PLATO instrument, for five months in 2008. From Yang et al. (2010).

For the future there is much work to be done in analysing the large amount of available satellite data showing PWV over the continent. The data need careful analysis to consider the line of sight of the satellite over the continent.
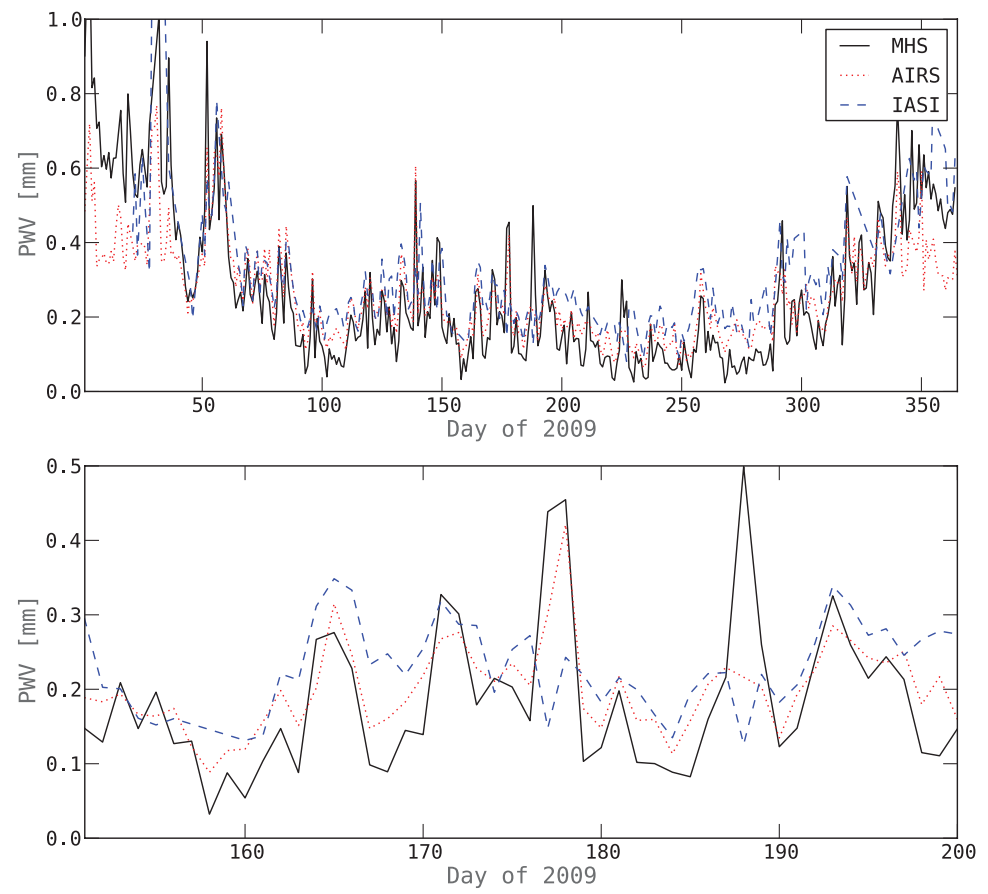

Figure 5. Daily averages of precipitable water vapour for Dome A in 2009 from three different satellite instruments (MHS, AIRS, and IASI), showing good agreement. Top: Spans the entire year. Bottom: Zooms in on a 50 day period during winter. From Sims et al. (2012). 


\section{Infrared sky brightness}

As predicted, the infrared sky over Antarctica has been found to be very dark. The following measurements, apart from one, refer to data from the US South Pole station.

At J $(1.25 \mu \mathrm{m})$ and $\mathrm{H}(1.65 \mu \mathrm{m})$, Phillips (1999) found a factor of 2-3 times improvement over Siding Spring Observatory (which is a very dark mid-latitude site); at these wavelengths, the sky background is dominated by airglow.

In the "cosmological window" at 2.27-2.45 $\mu \mathrm{m}$ ("Kdark") Ashley et al. (1996) and Nguyen et al. (1996) reported a factor of 100 improvement over mid-latitude sites. This is not as dark as expected, by at least a factor of two, and has yet to be satisfactorily explained.

In the L band $(2.9-4.1 \mu \mathrm{m})$ Ashley et al. (1996) and Phillips (1999) found a factor of 20-40 times improvement over Siding Spring.

From 4 to $14 \mu \mathrm{m}$ Chamberlin et al. (2000) found a factor of 10 improvement over Mauna Kea.

From 8.5 to $17 \mu \mathrm{m}$ Smith and Harper (1998) measured a factor of 10 improvement over Mauna Kea, and greatly improved temporal stability at $10 \mu \mathrm{m}$.

Away from the South Pole, the only infrared observations I am aware of are from Walden et al. (2005) who used an FTS to make summertime measurements at 3-20 $\mu \mathrm{m}$ from Dome C. The results were comparable to South Pole wintertime measurements from Smith and Harper (1998).

Interestingly, Lawrence (2004) predicted that Domes C and A will be substantially darker than the South Pole - factors of 2 to 100 from the near to far-IR - and with significant differences between the sites.

For the future we clearly need comprehensive infrared sky background measurements at 1-20 $\mu \mathrm{m}$ from Domes A, C, F. We also need further measurements at Kdark, ideally at high enough resolution to resolve any residual airglow lines.

It is worth considering that some of the earlier work from the South Pole may have been affected by aerosol variations in the atmosphere caused by volcanic eruptions (see Figure 6 and the discussion below in section 9).

\section{Atmospheric transmission variations arising from gases}

For precision optical photometry, the stability of the transmission of the atmosphere is an important consideration. Various molecules contribute, e.g., from $0.3-2.5 \mu \mathrm{m}$ we need to examine $\mathrm{H}_{2} \mathrm{O}, \mathrm{O}_{3}, \mathrm{O}_{2}, \mathrm{CO}_{2}, \mathrm{CH}_{4}, \mathrm{NO}_{2}, \mathrm{~N}_{2} \mathrm{O}$, and $\mathrm{CO}$. We have already discussed $\mathrm{H}_{2} \mathrm{O}$ in the section on precipitable water vapour.

Ozone is not often thought about in this context, but it turns out to be the dominant absorber through much of the optical. Apart from the Hartley bands that absorb in the ultraviolet, the Chappuis bands produce up to $\sim 10 \%$ absorption from $400-540 \mathrm{~nm}$. Ozone concentration is measured in Dobson Units (DU), where one DU is equivalent to a $10 \mu \mathrm{m}$ layer of pure ozone. Allen and Reck (1997) give a table showing the day-today variations in ozone concentration as a function of latitude on the Earth's surface. Mauna Kea and Paranal have variations of $\sim 4-5$ DU (this is the standard deviation of the absolute value of the difference from one day to the next). Sites further from the equator have larger variations, e.g., Siding Spring is $\sim 9$ DU. Allen and Reck's data do not extend to Antarctica. While ozone does fluctuate on monthly timescales in Antarctica-most notably the ozone hole that is prominent in spring - the day-to-day fluctuations at South Pole in wintertime are relatively small, although still greater than that at Mauna Kea and Paranal, at 10 DU (Evans 2012). 
The concentration of $\mathrm{CO}_{2}$ is steadily rising from anthropogenic fossil fuel use. It is quite well mixed throughout the atmosphere, and at all latitudes. There is a clear annual fluctuation of $\sim 2 \%$ peak-to-peak at Mauna Loa, resulting from vegetation growth cycles in the northern hemisphere. The variation is still present at the South Pole, but is significantly less at $\sim 0.4 \%$ peak-to-peak.

I have not considered the effect of $\mathrm{CH}_{4}, \mathrm{NO}_{2}, \mathrm{~N}_{2} \mathrm{O}$, and $\mathrm{CO}$. It would be interesting to do this, and to quantify the stability of the concentrations of all these molecules. This is relevant to understanding the ultimate limits of ground-based photometry.

\section{Optical sky brightness and aurora}

The optical sky background from Antarctica appears to be comparable to the best mid-latitude observatories, although there is much data that has been taken and not yet published. Zou et al. (2010) reports i-band sky brightness, and estimates that aurora affect $\sim 2 \%$ of observations, based on observations with CSTAR at Dome A in 2008 . Other measurements are available from ASTEP data at Dome C (Crouzet et al. 2010, 2011) and Nigel at Dome A (Sims et al. 2012). Data will soon be published from the Gattini experiments at Domes C, A and South Pole, and the HRCAM instruments on PLATO (Lawrence et al. 2009) at Domes A, F, and Ridge A.

For the future, our priority should be to publish the data that has been taken, and to continue to acquire uniform datasets. The strength of the airglow lines could be more thoroughly investigated, from the optical out to $2.4 \mu \mathrm{m}$. In common with other observatories, we expect a variation in sky brightness with the solar cycle, so long-term monitoring is important.

\section{Clouds}

Measuring the cloud cover over Antarctica during wintertime is complicated by the fact that few stations have a winterover crew; satellite instruments have difficulty in distinguishing cloud from the surface ice. Human "eye-ball" observations of eighths of cloud cover during winter are somewhat unreliable.

The first wintertime cloud observations from the high plateau were reported by the ICECAM experiment at Dome C (Ashley et al. 2005). This, and subsequent observations from Domes C and A (e.g., Zou et al. 2010, Crouzet et al. 2010, 2011), show significantly larger percentages of photometric conditions than mid-latitude sites. E.g., Zou et al. (2010) report $67 \%$ photometric $(<0.3 \mathrm{mag}$ extinction) conditions at Dome A during winter, compared with $\sim 50 \%$ for Mauna Kea.

For the future, both the Gattini and HRCAM experiments have acquired a large dataset of cloud statistics, and this is awaiting publication. Continuing to acquire a uniform record of the photometric conditions is very important, since this will help define the window functions which quantify the expected performance for, e.g., extrasolar planet transit and variable star campaigns.

\section{Meteorological properties}

We have a reasonable knowledge of the wind speed and direction, as a function of height, across the plateau. There are also balloon measurements of temperature as a function of height at South Pole and Dome C. Relative humidity measurements are difficult to make. A $15 \mathrm{~m}$ meteorological tower on PLATO acquired nine months of 
high quality data (temperature and wind speed/direction) from Dome A during 2011.

For the future, we need long-term meteorological towers of at least $15 \mathrm{~m}$ in height, instrumented with standard sensors, at Dome A, Dome F and Ridge A.

\section{Aerosols}

The "thumb test" (where you block out the sun using your thumb and look at the brightness of the surrounding sky) is an obvious indication to anyone that visits Antarctica that the aerosol concentrations are very low.

Recently, this has been quantified at Dome C by Dame et al. (2012) and Faurobert et al. (2012), showing that the sky is a factor of 2-4 times darker than Mauna Kea in the visible, and is dominated by Rayleigh scattering from molecules, not aerosols.

Tomasi et al. (2007) reviewed the observations of aerosols over Antarctica. The optical depth from aerosols at the South Pole is about 0.015 at $500 \mathrm{~nm}$, but increases dramatically following volcanic eruptions, as shown in Figure 6.

For the future, we should take aerosol optical depth into consideration when measuring sky transmission, stability, and the infrared sky brightness. Some of the historical measurements may need redoing during periods well away from volcanic activity.

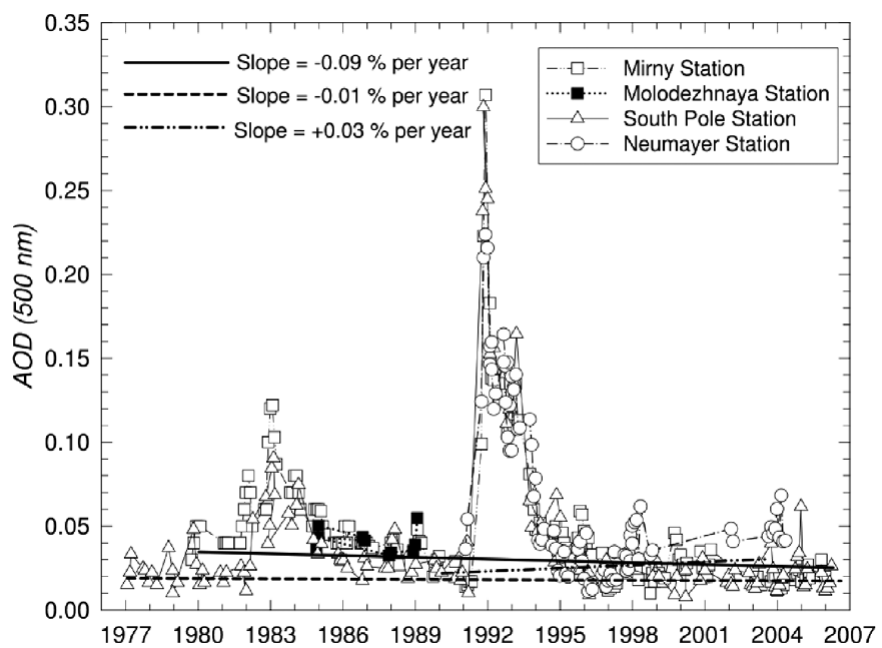

Figure 6. Time variation of the monthly mean aerosol optical depth (AOD) at $500 \mathrm{~nm}$ measured from four Antarctic stations. The peaks come immediately following volcanic eruptions: El Chichon in 1982 and Pinatubo and Cerro Hudson in 1991. From Tomasi et al. (2007).

\section{Conclusion}

In some respects, the Antarctic high plateau (Figure 7) is one of the best characterised astronomical sites. The measurements have in most cases confirmed Antarctica as having the best locations on Earth for ground-based observations. There are some important measurements still to be made, notably the infrared sky backgrounds at sites other than the South Pole, and the seeing at Dome A. In both of these examples, there are theoretical reasons for expecting significant improvements that are still to be revealed. 


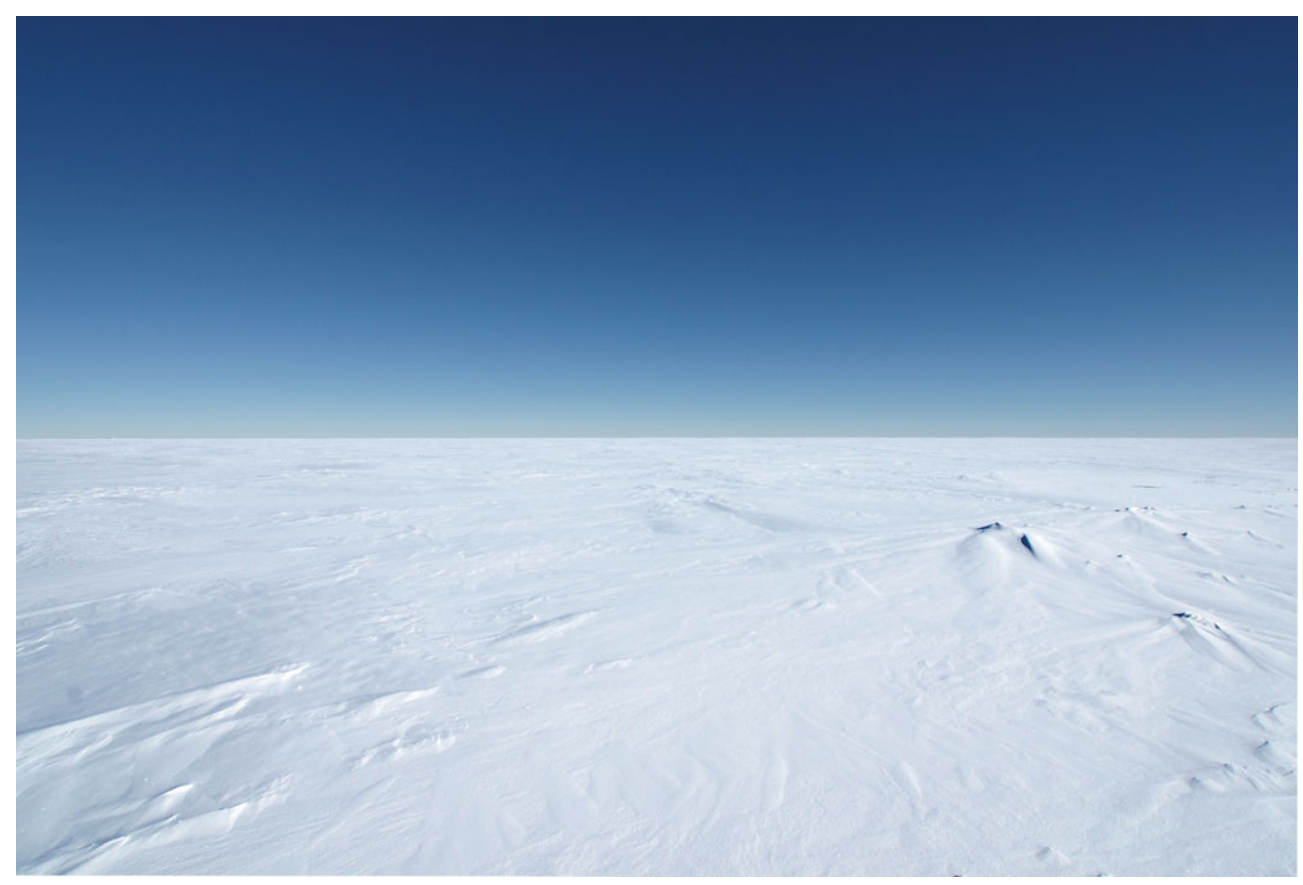

Figure 7. The Antarctic plateau, $3 \mathrm{~km}$ from the US Amundsen-Scott South Pole Station, January 2012. M. Ashley.

\section{References}

Agabi, A., Aristidi, E., Azouit, M., Fossat, E., Martin, F., Sadibekova, T., Vernin, J., \& Ziad, A. $2006, P A S P, 118,344$

Allen, D. R. \& Reck, R. A. 1997, JGR, 102, 13603-13608

Argentini, S., Mastrantonio, G., Petenko, I., Pietroni, I., \& Viola, A. 2012, Boundary-layer Meteorology 2012, 143, 177-188

Aristidi, E., Agabi, A., Fossat, E., Azouit, M., Martin, F., Sadibekova, T., Travouillon, T., Vernin, J., et al. 2005, A\& $A, 444,651$

Aristidi, E., Fossat, E., Agabi, A., Mkarnia, D., Jeanneaux, F., Bondoux, E., Challita, Z., Ziad, A., Vernin, J., et al. 2009, A\&A, 499, 955

Ashley, M. C. B., Burton, M. G., Storey, J. W. V., Lloyd, J. P., Bally, J., Briggs, J. W., \& Harper, D. A. 1996, PASP, 108, 721-723

Ashley, M. C. B., Burton, M. G., Calisse, P. G., Phillips, A., \& Storey, J. W. V. 2005, Highlights of Astronomy, ASP Conference Series, 13, 936-938

Bonner, C. S., Ashley, M. C. B., Lawrence, J. S., Luong-Van, D. M., \& Storey, J. W. V. 2009, Acoustics Australia, 37, 47-51

Bonner, C. S., Ashley, M. C. B., Cui, X., Feng, L., Gong, X., Lawrence, J. S., Luong-van, D. M., Shang, Z., Storey, J. W. V., Wang, L., Yang, H., Yang, J., Zhou, X., \& Zhu, Z. 2010, PASP, 122, 1122-1131

Burton, M. G. 2010, A\&SARev, 18, 417-469

Chamberlain, M. A., Ashley, M. C. B., Burton, M. G., Phillips, A., Storey, J. W. V., \& Harper, D. A. $2000, A p J, 535,501-511$

Crouzet, N., Guillot, T., Agabi, A., Rivet, J., Bondoux, E., et al. 2010, A\&\&A, 511, 36

Crouzet, N., Guillot, T., Agabi, K., Daban, J.-B., Abe, L., Mekarnia, D., Rivet, J.-P., FanteCaujolle, Y., Fressin, F., Gouvret, C., Schmider, F.-X., Valbousquet, F., Blazit, A., Rauer, H., Erikson, A., Fruth, T., Aigrain, S., Pont, F., \& Barbieri, M. 2011, EPJ Web of Conferences, 11, 06001

Dame, L., Abe, L., Faurobert, M., Fineschi, S., Kuzin, S., Lamy, P., Meftah, M., \& Vives, S. 2012, EAS Publications Series, 55, 359-364 
Evans, R., 2012, Private communication, based on 2011 South Pole data, NOAA.

Faurobert, M., Arnaud, J., \& Vernisse, Y. 2012, EAS Publications Series, 55, 365-367

Gillingham, P. 1993, Optics in Astronomy, Proceedings of the 32nd Hestmonceux Conference held in 11993. Edited by J.V. Wall. Cambridge, UK: Cambridge University Press, p. 244

Giordano, C., Vernin, J., Chadid, M., Aristidi, E., Agabi, A., \& Trinquet, H. 2012 PASP, 124, 494-506

Harper, D. A. 1989, Astrophysics in Antarctica, American Institute of Physics, 123-129

Kenyon, S. L., Lawrence, J. S., Ashley, M. C. B., Storey, J. W. V., Tokovinin, A.,\& Fossat, E. 2006, PASP, 118, 924-932

Lascaux, F., Masciadri, E., \& Hagelin, S. 2011, MNRAS, 411, 693-704

Lawrence, J. S. 2004, PASP, 116, 482-492

Lawrence, J. S., Ashley, M. C. B., Tokovinin, A., \& Travouillon, T. 2004, Nature, 431, 278-281

Lawrence, J. S., Ashley, M. C. B., Hengst, S., Luong-Van, D. M., Storey, J. W. V., Yang, H., Zhou, X., \& Zhu, Z. 2009, Rev. Sci. Inst., 80, 064501-1-064501-10

Loewenstein, R. F., Bero, C., Lloyd, J. P., Mrozek, F., Bally, J., \& Theil, D. 1998, ASP Conf Series, 141, 296

Lubin, D. 1988, Masters thesis, University of Chicago

Marks, R. D., Vernin, J., Azouit, M., Briggs, J. W., Burton, M. G., Ashley, M. C. B., \& Manigault, J.-F. 1996, A\&SA Suppl, 118, 385-390

Marks, R. D., Vernin, J., Azouit, M., Manigault, J. F., \& Clevelin, C. 1999, A\&\&A Suppl, 134, $161-172$

Neff, W. D. 1981, PhD thesis, Wave Propagation Laboratory (Boulder Colorado, USA)

Nguyen, H. T., Rauscher, B. J., Harper, D. A., Loewenstein, R. F., Pernic, R. J., Severson, S. A., \& Hereld, M. 1996, PASP, 109, 718

Phillips, A., Burton, M. G., Ashley, M. C. B., Storey, J. W. V., Lloyd, J. P., Harper, D. A., \& Bally, J. 1999, ApJ 527, 1009-1022

Sims, G., Ashley, M. C. B., Cui, X., Everett, J. R., Feng, L., Gong, X., Hengst, S., Hu, Z., Kulesa, C., Lawrence, J. S., Luong-van, D. M., Ricaud, P., Shang, Z., Storey, J. W. V., Wang, L., Yang, H., Yang, J., Zhou, X., \& Zhu, Z., 2012 2012, PASP, 124, 74-83

Sims, G., Ashley, M. C. B., Cui, X., Everett, J. R., Feng, L., Gong, X., Hengst, S., Hu, Z., Lawrence, J. S., Luong-Van, D. M., Moore, A. M., Riddle, R., Shang, Z., Storey, J. W. V., Tothill, N., Travouillon, T., Wang, L., Yang, H., Yang, J., Zhou, X., \& Zhu, Z. 2012, PASP, $124,637-649$

Smith, C. H. \& Harper, D. A. 1998, PASP, 110, 747

Swain M. \& Gallée, H. 2006, PASP, 118, 1190

Tomasi, C., Vitale, V., Lupi, A., Di Carmine, C., Campanelli, M., Herber, A., Treffeisen, R., Stone, R. S., Andrews, E., Sharma, S., Radionov, V., von Hoyningen-Huene, W., Stebel, K., Hansen, G. H., Myhre, C. L., Wehrli, C., Aaltonen, V., Lihavainen, H., Virkkula, A., Hillamo, R., Strm, J., Toledano, C., Cachorro, V. E., Ortiz, P., de Frutos, A. M., Blindheim, S., Frioud, M., Gausa, M., Zielinski, T., Petelski, T., \& Yamanouchi, T. 2012, JGR, 112, D12205

Tremblin, P., Minier, V., Schneider, N., Durand, G. A., Ashley, M. C. B., Lawrence, J. S., Luong-van, D. M., Storey, J. W. V., Durand, G. A., Reinert, Y., Veyssiere, C., Walter, C., Ade, P., Calisse, P. G., Challita, Z., Fossat, E., Sabbatini, L., Pellegrini, A., Ricaud, P., \& Urban, J. 2011, $A \mathscr{E} A$, 535, A112

Trinquet, H., Agabi, A., Vernin, J., Azouit, M., Aristidi, E., \& Fossat, E. 2008, PASP, 120, 203

Walden, V. P., Town, M. S., Halter, B., \& Storey, J. W. V. 2005, PASP, 117, 300-308

Yang, H., Kulesa, C. A., Walker, C. K., Tothill, N. F. H., Yang, J., Ashley, M. C. B., Cue, X., Feng, L., Lawrence, J. S., Luong-Van, D. M., Storey, J. W. V., Wang, L., Zhou, X., \& Zhu, Z. 2010, PASP, 122, 490-494

Zou, H., Zhou, X., Jiang, Z., Ashley, M. C. B., Cui, X., Feng, L., Gong, X., Hu, J., Kulesa, C. A., Lawrence, J. S., Liu, G., Luong-Van, D. M., Ma, J., Moore, A. M., Pennypacker, C. R., Qin, W., Shang, Z., Storey, J. W. V., Sun, B., Travouillon, T., Walker, C. K., Wang, J., Wang, L., Wu, J., Wu, Z., Xia, L., Yan, J., Yang, J., Yang, H., Yao, Y., Yuan, X., York, D. G., Zhang, Z., \& Zhu, Z. 2010, AJ, 140, 602-611 